\title{
IPTU Premiado: uma estratégia de arrecadação
}

\author{
Luan Soura dos Anjos' \\ Iracildo Silva Santos ${ }^{2}$ \\ Solange R. Santos Corrêa ${ }^{3}$
}

\begin{abstract}
Resumo: Este trabalho trata de políticas de arrecadação voltadas para a elevação de receitas próprias municipais, o denominado IPTU Premiado, medida de incentivo à arrecadação, fundada em estímulos econômicos, com o objetivo principal de estimular a participação desse imposto nas receitas do município. A questão que orientou a investigação e o estudo está centrada na seguinte indagação: A campanha "IPTU Premiado" gera mais receitas para o município promotor? Diante do contexto de crise econômica, conhecer ações governamentais capazes de elevar as receitas próprias, torna-se de grande relevância para as funções de planejamento e gestão governamentais. A pesquisa dota como universo Itabuna, na Bahia, município integrante da região chamada "Costa do Cacau". Para alcançar o objetivo, inicialmente foram coletados, no sítio do Portal da Transparência daquele município, os valores referentes às previsões orçamentárias. De forma complementar, foram solicitados relatórios ao arquivo público do município, por meio do Sistema de Informação ao Cidadão Eletrônico (e-SIC). Os resultados do estudo demonstram a efetividade da medida, porquanto houve elevação das receitas próprias do município.
\end{abstract}

Palavras-chave: Inovação. Incentivo. Premiação. Receitas.

Resumen: Este trabajo trata de políticas de recaudación dirigidas a la elevación de ingresos propios municipales, se trata del IPTU Premiado, medida de incentivo a la recaudación, fundada en estímulos económicos, con el objetivo principal de estimular la participación del IPTU en los ingresos del municipio. La elección del tema se dio mediante el inminente retroceso de los traspasos constitucionales a los municipios como consecuencia del proceso de recesión adoptado por el gobierno federal brasileño a partir de 2015. A partir de esta visión se propone la siguiente pregunta para orientar la investigación: la campaña "IPTU Premiado" genera más ingresos para el municipio promotor? El objetivo de este estudio es, por lo tanto, verificar si la campaña "IPTU Premiado" genera más ingresos para el municipio promotor. Ante el contexto de crisis económica, conocer acciones gubernamentales capaces de elevar los ingresos propios, se vuelve de gran relevancia para las funciones de planificación y gestión gubernamentales. La investigación dota como universo, el Municipio de Itabuna/Bahía, integrante de la región llamada "Costa do Cacau". Para alcanzar el objetivo, inicialmente se recogió junto al sitio del Portal de la Transparencia del Municipio los valores referentes a las previsiones presupuestarias. De forma complementaria fueron solicitados informes al archivo público del municipio, a través del Sistema de Información al Ciudadano Electrónico (e-SIC) . Los hallazgos del estudio demuestran la efectividad de la medida con la elevación de los ingresos propios del municipio.

Palabras clave: Innovación. Incentivo. Premiación. Recetas.

\footnotetext{
${ }^{1}$ Bacharel em Ciências Contábeis pela Universidade Estadual de Santa Cruz (UESC). E-mail: 1sanjos@hotmail.com.

${ }^{2}$ Mestre em Economia Regional e Políticas Públicas, docente da Universidade Estadual de Santa Cruz (UESC). E-mail: iracildoss@gmail.com.

${ }^{3}$ Doutora em Ciências Sociais, Desenvolvimento, Agricultura e Sociedade pela UFRRJ. Docente da Universidade Estadual de Santa Cruz (UESC). E-mail: srscorrea@uesc.br.
}

Página 205 Caderno de Ciências Sociais Aplicadas, Vitória da Conquista/BA, vol. 15, n 26, ano 15, p. 205-221, jul/dez 2018. 


\section{Introdução}

As sucessivas crises fiscais que vêm ocorrendo na administração pública brasileira e mundial exigem transformações estruturais e funcionais para que o Estado, provedor do bem-estar social, obtenha impactos positivos no desenvolvimento e na democracia local, na perspectiva de criar, aperfeiçoar, fortalecer e institucionalizar mecanismos e estruturas inovadoras para a solução dos problemas e o atendimento das demandas legítimas da sociedade (KNOPP; ALCOFORADO, 2010). Novas políticas públicas e inovações no processo de produção e provisão de serviços públicos assumem grande relevância para as funções de planejamento e gestão governamental.

Com o intuito de proporcionar o bem-estar social, os administradores públicos procuram utilizar ferramentas capazes de aumentar a arrecadação tributária, na expectativa de suprir as despesas orçamentárias para atender às necessidades básicas dos cidadãos. Segundo Soares, Flores e Coronel (2014), investimentos em recursos tecnológicos e o combate à sonegação fiscal, aliados à conscientização do cidadão no que se refere ao dever e a importância de pagar imposto, são alguns dos procedimentos considerados indispensáveis para concretização e elevação da arrecadação tributária.

Uma medida inovadora para impulsionar a arrecadação tributária no âmbito municipal e que se refere à arrecadação do imposto territorial e predial urbano (IPTU) é o "IPTU Premiado". Trata-se de uma política de incentivo à arrecadação fundada em estímulos financeiros, cuja finalidade é impulsionar o contribuinte a ficar em dia com suas obrigações fiscais, almejando, assim, elevar os níveis de arrecadação do imposto nas receitas próprias.

Em 2013 foi instituída no município de Itabuna/BA, a Lei n 2.225, denominada "IPTU Premiado", programa de educação tributária que incentiva os cidadãos a colaborarem com os esforços da administração municipal em investir recursos em benefício da própria população. A premiação é uma forma de valorizar os contribuintes que pagam os seus impostos em dia e incentivar o cidadão a igualmente realizar eventuais pagamentos de débitos existentes, além de ser um meio alternativo que intenta ampliar a arrecadação de recursos para obras de melhorias no município.

Entretanto, segundo DIAS (2013), ao incentivar a arrecadação de impostos mediante concessão de descontos e sorteios de prêmios, é importante ressaltar que os custos de funcionamento e manutenção dessas políticas de arrecadação devem ser os menores possíveis, de modo a atender aos demais objetivos da política orçamental. Encontrar alternativas capazes de aumentar a arrecadação de receitas próprias torna-se, portanto, um grande desafio para os gestores municipais. Com base nessa

Página 206 Caderno de Ciências Sociais Aplicadas, Vitória da Conquista/BA, vol. 15, n 26, ano 15, p. 205-221, jul/dez 2018. 
visão, propõe-se a seguinte pergunta para orientar a investigação: A campanha "IPTU Premiado" gera mais receitas para o município promotor?

O município de Itabuna/BA, objeto de estudo desta pesquisa, conceituado, tal como a cidade de Ilhéus/BA, de "Capital Regional B” (GUIMARÃES, 2012, p. 29) "Capital do Sul da Bahia", é considerado um dos mais desenvolvidos da região Sul estado da Bahia, porquanto possui uma economia que representa o $10^{\circ}$ maior PIB do estado. Para incrementar ainda mais o desenvolvimento, instituiu, em 2013, a Lei Municipal n² 2.225, denominada "IPTU Premiado", fundada em estímulos financeiros, com o objetivo de incentivar os contribuintes do Imposto Predial e Territorial Urbano (IPTU) a ficarem em dias com suas obrigações fiscais e, consequentemente, estimular o a arrecadação do imposto no município.

Diante do contexto de crise econômica, conhecer ações governamentais capazes de elevar as receitas próprias torna-se de grande relevância para as funções de planejamento e gestão governamentais, uma vez que, segundo Duarte e Alcântara (2013), em tempos de escassez de recursos o reconhecimento da boa arrecadação pode exprimir um salto de qualidade nas políticas públicas, garantir os investimentos e melhorar a vida do cidadão.

\section{Referencial teórico}

A revisão de literatura foi elaborada com vistas à sustentação teórica dos conceitos abordados neste trabalho. A atenção concentrou-se inicialmente no papel dos tributos nas finanças públicas, passando por questões de inovações na gestão pública, voltando-se, fundamentalmente para o IPTU.

\section{O Papel do tributo nas finanças públicas}

Para garantir os direitos mínimos constitucionais e a realização de políticas públicas voltadas às necessidades básicas dos cidadãos, as entidades estatais precisam obter recursos financeiros. O Estado, ente político criado para atender as necessidades coletivas, pode desempenhar relevante papel como agente capaz de fomentar a arrecadação tributária. Por intermédio da arrecadação, o governo obtém os recursos financeiros necessários para atender as múltiplas funções e tarefas a ele atribuídas (ROTHMANN, 1972). Talvez os primeiros registros documentados sobre o pagamento de

Página 207 Caderno de Ciências Sociais Aplicadas, Vitória da Conquista/BA, vol. 15, n 26, ano 15, p. 205-221, jul/dez 2018. 
tributos estejam nas Escrituras Hebraicas, no primeiro livro da Bíblia Sagrada, no livro de Gêneses, em que há a seguinte declaração:

Há de ser, porém, que no tempo das colheitas dareis a quinta parte a Faraó, e quatro partes serão vossas, para semente do campo, e para o vosso mantimento e dos que estão nas vossas casas, e para o mantimento de vossos filhinhos (Gn. 47:24).

Em outro trecho da bíblia, transcrito a seguir, o próprio Jesus Cristo, mostrou uma posição coerente acerca da arrecadação de impostos:

Dize-nos, pois, que te parece? É lícito pagar o tributo a César, ou não? $[\ldots]$

Mostrai-me a moeda do tributo. E eles lhe apresentaram um dinheiro. E ele diz-lhes: De quem é esta efígie e esta inscrição? Dizem-lhe eles: De César. Então ele lhes disse: Dai, pois a César o que é de César, e a Deus o que é de Deus (Mt. 22:17, 19-21).

Na Europa, durante o período da Revolução Francesa, século XVIII, há vários registros da cobrança de impostos. À medida que a guerra civil se prolongava e ficava mais cara, os governos europeus se tornaram mais centralizados e adeptos do recolhimento de impostos, retirando de forma coercitiva a riqueza da burguesia e o pouco que os camponeses possuíam. Essa época ficou conhecida como antigo regime (LONGO, 2006).

No Brasil, a primeira Constituição republicana brasileira, de 24 de fevereiro de 1891, instituiu o regime de separação de fontes tributárias, sendo discriminados os impostos de competência exclusiva da União e dos estados. Em 16 de julho de 1934, a nova Constituição, atribuiu aos Estados o imposto de vendas e consignações, além de dar competência tributária para os municípios. A Constituição de 1946 atribuiu ao município, competência exclusiva para instituir os impostos: territorial urbano, rural e predial (VARSANO, 1996).

A Constituição Federal de 1988 criou o sistema tributário nacional, bem como conservou e ampliou o grau de autonomia fiscal dos estados e municípios (COSTA, 1994), além de estabelecer os objetivos fundamentais da União. A União dispõe de meios para a realização desses objetivos, que se expressam no poder de tributar, isto é, instituir leis que obriguem o cidadão a entregar valores aos cofres públicos, independentemente da sua vontade, considerando a capacidade econômica do contribuinte (ALEXANDRE, 2015). Portanto, o dever de pagar tributo é imposto pela lei, somente a

Página 208 Caderno de Ciências Sociais Aplicadas, Vitória da Conquista/BA, vol. 15, n 26, ano 15, p. 205-221, jul/dez 2018. 
lei pode obrigar alguém a fazer ou deixar de fazer algo, conforme o art. $5^{\circ}$, inciso II da Constituição Federal brasileira.

Segundo Alexandre (2015), o imposto sustenta-se na ideia de solidariedade social, as pessoas ficam obrigadas a contribuir com o Governo, fornecendo-lhe os recursos de que este precisa para buscar a consecução do bem comum. Os impostos são, por definição, tributos não vinculados, ou seja, não é permitida a vinculação de sua receita a órgão, fundo ou despesa, e incidem sobre manifestações de riqueza do contribuinte. Assim, aqueles que obtêm rendimentos, vendem mercadorias, são proprietários de imóveis em área urbana, por exemplo, devem contribuir respectivamente com a União, o Imposto de Renda (IR), os Estados, Imposto sobre Circulação de Mercadorias e Serviços (ICMS) e municípios, Imposto Predial e Territorial Urbano (IPTU).

Apesar de caracterizar-se como um instrumento do poder executivo para manter sua própria estrutura, o tributo pode desempenhar outras funções em uma perspectiva não arrecadatória, denominada extrafiscalidade. Por meio desta, a administração pública pode valer-se de normas tributárias para estimular ou desestimular certas atividades econômicas, sendo lícito aos agentes econômicos decidirem se adotam ou não a conduta pretendida pela autoridade administrativa (KALIL; GONÇALVES, 2016). Assim sendo, o tributo possui uma importante função social, cumprida com a destinação não arrecadatória da atividade tributária conferida pelo Estado, conhecida como extrafiscalidade, que se utiliza dos tributos para propiciar impactos diretos sobre a economia e o comportamento das pessoas.

\section{Repartição das receitas tributárias}

O sistema tributário nacional é regido pelo disposto na Emenda Constitucional $n^{\circ} 18$, de $1^{\circ}$ de dezembro de 1965, em leis complementares, resoluções do Senado Federal e, nos limites das respectivas competências, em leis federais, estaduais e municipais (BRASIL, 1965). Segundo Alexandre (2015, p. 59), “a Constituição Federal não cria tributos, apenas atribui competência para que os entes políticos o façam".

A arrecadação federal é composta de impostos, taxas e contribuições, sendo sua arrecadação repartida entre os entes federados. A Constituição Federal de 1988, nos artigos 153 e 154, estabelece os impostos cuja competência ordinária para arrecadação é da União.

Página 209 Caderno de Ciências Sociais Aplicadas, Vitória da Conquista/BA, vol. 15, n 26, ano 15, p. 205-221, jul/dez 2018. 
No âmbito estadual, esferas governamentais de nível intermediário, os recursos financeiros provêm basicamente da arrecadação tributária própria e de repasses federais. O art. 155 da Constituição Federal prevê os impostos cuja competência de arrecadação é exclusiva dos estados: Imposto de Transmissão Causa Mortis e doação (ITCMD), Imposto sobre Circulação de Mercadorias e Serviços (ICMS) e Imposto sobre a Propriedade de Veículos Automotores (IPVA). A Constituição prevê, ainda, no art. 157, os impostos que, apesar de não serem de competência arrecadatória dos estados, compõem suas receitas.

Já nos municípios, as receitas são compostas pela arrecadação do Imposto Predial e Territorial Urbano (IPTU), Transmissão Inter Vivos de Bens Imóveis (ITBI) e Serviços de Qualquer Natureza (ISSQN), de acordo com o art. 156 da CF. Integram ainda as receitas municipais, recursos provenientes de repasses dos governos federal e estadual, conforme 158 da Constituição. As parcelas de receita pertencentes aos municípios serão creditadas proporcionalmente ao valor das respectivas arrecadações, em seus territórios, de acordo com o que dispuser a lei estadual (IPVA e ICMS), ou federal (IR e ITR Propriedade Territorial Rural), de acordo com o art. 158, parágrafo único, incisos I e II da Constituição Federal.

Quadro 1 - Repartição de receitas tributárias entre os entes federados

\begin{tabular}{|c|c|c|c|c|}
\hline Tributos de Competência da União - Art. 153 & União & Estado & Município & $\begin{array}{l}\text { Reg. N. } \\
\text { NE. CO }\end{array}$ \\
\hline I - Importação de produtos estrangeiros & $100 \%$ & - & - & - \\
\hline IE - Exportação & $90 \%$ & $10 \%$ & - & - \\
\hline IR - Renda e proventos de qualquer natureza & $53 \%$ & $21,50 \%$ & $22,50 \%$ & $3 \%$ \\
\hline IPI - Produtos Industrializados & $53 \%$ & $21,50 \%$ & $22,50 \%$ & $3 \%$ \\
\hline IOF - Operações de Crédito, Câmbio e Seguro & $100 \%$ & - & - & - \\
\hline ITR - Propriedade Territorial Rural & $50 \%$ & - & $50 \%$ & - \\
\hline IGF - Grandes Fortunas & $100 \%$ & - & - & - \\
\hline Tributos de competência dos Estados - Art. 155 & União & Estado & Município & $\begin{array}{l}\text { Reg. N. } \\
\text { NE. CO }\end{array}$ \\
\hline ITBI - Transm. Bens Imóveis e Doação (Causa Mortis) & - & $100 \%$ & - & - \\
\hline ICMS - Circulação Mercadorias e Serviços & - & $75 \%$ & $25 \%$ & - \\
\hline IPVA - Propriedades de Veículos Automotores & - & $50 \%$ & $50 \%$ & - \\
\hline Tributos de competência dos municípios - Art. 156 & União & Estado & Município & $\begin{array}{l}\text { Reg. N. } \\
\text { NE. CO }\end{array}$ \\
\hline IPTU - Predial e Territorial Urbano & - & - & $100 \%$ & - \\
\hline
\end{tabular}

Página 210 Caderno de Ciências Sociais Aplicadas, Vitória da Conquista/BA, vol. 15, n 26, ano 15, p. 205-221, jul/dez 2018. 


\begin{tabular}{|l|l|l|l|l|}
\hline ITBI - Transmissão Inter Vivos de Bens Imóveis & - & - & $100 \%$ & - \\
\hline ISSQN - Serviços de Qualquer Natureza & - & - & $100 \%$ & - \\
\hline
\end{tabular}

Fonte: Adaptado da Constituição Federal de 1988.

Assim, 21,5\% do IPI e IR, excluindo o IRRF, pertencem integralmente aos Estados, e são repassados aos cofres dos estados por meio do Fundo de Participação dos Estados (FPE). Assim, $22,5 \%+1 \%$ da arrecadação do IPI e do IR, excluindo a parcela do IRRF, pertencem integralmente aos municípios, transferidos pelo Fundo de Participação dos Municípios (FPM). Por intermédio do fundo constitucional de financiamento do Norte (NO), Nordeste (NE) e Centro-Oeste (CO) são repassados $3 \%$ do total da arrecadação do IPI e do IR destinados ao desenvolvimento econômico e social mediante programas de financiamento aos setores produtivos das regiões.

\section{O Imposto Predial e Territorial Urbano}

De modo geral, os poderes locais incumbem-se de arrecadar o imposto imobiliário, visto que conhecem melhor a zona urbana da cidade. Esse imposto constitui, portanto, uma importante fonte de receita para as jurisdições locais (CARVALHO JR., 2006). Ainda segundo o autor, no Brasil, o IPTU é fundamental para o financiamento das atividades financeiras, bem como para contribuir na distribuição de renda e captura de "mais-valia", decorrente de valorização imobiliária gerada fundamentalmente por investimentos públicos.

O IPTU é um tributo tipicamente local, que onera os proprietários de imóveis localizados na área urbana do município. De acordo com Afonso et al. (2013, p 57) “o IPTU é um tributo direto e os contribuintes costumam fazer estreita correlação entre o seu pagamento e os benefícios que podem obter”. Entretanto, a arrecadação desse imposto ajuda a compor o conjunto dos recursos próprios do município com os quais a prefeitura financia todas as suas atividades, ou seja, o IPTU pode ser utilizado em quaisquer despesas previstas no orçamento (CF, art. 167, IV) e não nas de interesse do proprietário do imóvel, por exemplo.

A apuração desse imposto é feita mediante a aplicação de uma alíquota ao valor venal do imóvel, que resulta do somatório do valor do terreno com o valor atribuído à edificação, definido por um conjunto de elementos que incluem a área do terreno, localização, característica (comercial ou residencial) etc (AFONSO; ARAÚJO; NÓBREGA, 2013). Para determinar a base de cálculo, estima-se o preço mais provável de venda do imóvel em condições normais de negociação (SÁ, 2015). De acordo

Página 211 Caderno de Ciências Sociais Aplicadas, Vitória da Conquista/BA, vol. 15, n 26, ano 15, p. 205-221, jul/dez 2018. 
com o art. 33 do Código Tributário Nacional, não se considera o valor dos bens móveis mantidos, em caráter permanente ou temporário, no imóvel para efeito de sua utilização, exploração, ou comodidade, na determinação da base de cálculo do IPTU.

Segundo Garson (2001), apesar da legislação, e de o IPTU ser o mais antigo imposto municipal do Brasil, sua arrecadação ainda é pouco significativa. Afonso et al. (2013) destacam: “o IPTU não representa uma importante fonte de recursos tributários próprios para a maioria das prefeituras brasileiras". Para a mudança dessa situação, Garson (2001) defende uma agenda de trabalho que inclua estudos e redesenho da legislação, informatização do cadastro imobiliário, adequação dos cálculos de avaliação dos imóveis, controle da arrecadação e cobrança por meio de sistemas informatizados, e medidas que elevem a produtividade do IPTU, imposto mais adequado para atender à necessidade de expansão das receitas próprias.

\section{Inovação na gestão pública}

De acordo com Schwella (2005, p. 264) “a busca pela boa governança é uma das atuais “megatendências" e um dos desafios da liderança pública". Segundo Marini (2008), desde o início dos anos 1980 são debatidas questões sobre o papel do Estado, especialmente com relação à exigência de uma nova governança capaz de promover o desenvolvimento econômico e social, com o auxílio de mecanismos inovadores de relacionamento com a sociedade. Participação e transparência, aliadas à capacidade informatizacional da instituição governamental e à geração e difusão de tecnologias, são ferramentas capazes de transformar o local em um meio inovador.

A criação de mecanismos de participação e controle pode ser uma resposta à escassez de recursos em muitos municípios. Inovações introduzidas na gestão pública, como a modernização da gestão pública, participação social e responsabilidade social, são importantes instrumentos na busca do desenvolvimento e fortalecimento das instituições governamentais (ALCOFORADO, 2009). Um novo cenário localista se impõe no Brasil, em decorrência da crescente institucionalização da política e do desenvolvimento socioeconômico na escala municipal, engendrados por estratégias institucionais, visando o fortalecimento econômico e a melhoria da qualidade de vida da população.

Para Silva (2014), as mudanças no papel e na função do Estado são uma importante tendência para o desenvolvimento da administração pública. Trata-se de uma nova forma de "fazer" do Estado, que contribui para uma gestão pública mais condizente com o tamanho, as mudanças e a complexidade

Página 212 Caderno de Ciências Sociais Aplicadas, Vitória da Conquista/BA, vol. 15, n 26, ano 15, p. 205-221, jul/dez 2018. 
dos problemas sociais. O fato é que muitos municípios brasileiros passaram a canalizar um crescente número de iniciativas políticas e econômicas inovadoras, destinadas a resolver sérios problemas que afetam as coletividades locais.

O "IPTU Premiado" é uma estratégia política de incentivo à arrecadação, fundada em estímulos financeiros. A finalidade é estimular o contribuinte a ficar em dia com suas obrigações fiscais, almejando assim, elevar os níveis de arrecadação do imposto. O programa de incentivo à arrecadação, que sorteia prêmios aos contribuintes que cumprem com suas obrigações tributárias em dia, é uma alternativa à necessária recuperação do quadro econômico-fiscal municipal.

\section{Metodologia}

Para discutir o tema central da pesquisa, utilizou-se inicialmente de levantamento bibliográfico, com a leitura de livros, artigos científicos, revistas, manuais e legislações. O método utilizado foi uma abordagem qualitativa com caráter descritivo. Segundo Gil (2008), a pesquisa bibliográfica é desenvolvida com base em materiais já publicados, constituído principalmente de livros e artigos científicos, e permite ao investigador a cobertura mais ampla sobre determinado assunto, mediante um novo enfoque. A abordagem qualitativa responde a questões muito particulares, aprofunda-se no mundo dos processos e dos fenômenos e, trabalha com o universo de significados, motivos, aspirações, crenças, valores e atitudes (MINAYO, 2001). A pesquisa com caráter descritivo expõe características de determinada população ou de determinado fenômeno; a utilização de técnicas padronizadas de coleta de dados são as características mais significativas desse tipo de pesquisa (GIL, 2008).

Para alcançar o objetivo, foi realizada uma pesquisa documental por meio da coleta de dados no sítio do Portal da Transparência do Município. Foram analisados os valores referentes às previsões orçamentárias, e, de forma complementar, solicitados ao arquivo público do município relatórios do Sistema de Informação ao Cidadão Eletrônico (e-SIC). Segundo Gil (2008), a pesquisa documental consiste na exploração das fontes documentais, utilizando-se de materiais que não receberam ainda um tratamento analítico, ou que ainda podem ser reelaborados de acordo com os objetivos da pesquisa.

Os dados coletados referem-se à arrecadação do imposto no município de Itabuna, na Bahia, no período compreendido entre 2005 e 2015, visto que não foram divulgados valores relativos ao ano de 2016. O modelo de análise adotado para inferência em torno do IPTU Premiado no comportamento

Página 213 Caderno de Ciências Sociais Aplicadas, Vitória da Conquista/BA, vol. 15, n 26, ano 15, p. 205-221, jul/dez 2018. 
da arrecadação tributária do município de Itabuna adotou o ano de 2012 como base para o estudo, em virtude, de ser anterior ao início da campanha "IPTU Premiado".

Quadro 2 - Esquema de Análise

\begin{tabular}{|c|c|c|c|}
\hline 2012 & 2013 & 2014 & 2015 \\
\hline \multirow{2}{*}{$\begin{array}{c}\text { Ano base de } \\
\text { observação }\end{array}$} & Ano vigência da Lei & \multirow{2}{*}{ Análise } & Análise \\
\cline { 2 - 2 } & Análise & Ane & \\
\hline
\end{tabular}

Fonte: Elaborado pelos autores, 2016.

O quadro 2 evidencia o modelo de análise adotado para inferência em torno do IPTU Premiado no comportamento da arrecadação tributária do município de Itabuna, na Bahia.

\section{Resultados e discussões}

O município de Itabuna/BA, onde a pesquisa foi realizada, é considerado um das mais desenvolvidos da região Sul do estado da Bahia, situado às margens da BR-101 e BR-415, com população estimada em 212.000 habitantes, segundo o Instituto Brasileiro de Geografia e Estatística (IBGE, 2010). Sua importância econômica cresceu no Brasil durante a época áurea do cultivo de cacau, com o $2^{\circ}$ lugar em produção no país, exportando para os Estados Unidos e Europa. Hoje a economia do município representa o $10^{\circ}$ maior PIB do estado, sustentada pelo comércio e indústrias de grande porte, consolidando-se também como polo médico, prestador de serviços e de educação.

Em 2013, foi instituída no município de Itabuna/BA, a Lei $\mathrm{n}^{\circ} 2.225$, denominada "IPTU Premiado", programa de educação tributária, que incentiva os cidadãos a colaborarem com os esforços da administração municipal para investir recursos em benefício da própria população. Essa Lei estabelece que o valor total dos prêmios objeto do sorteio não poderá ser superior a 10\% (dez por cento) do total efetivamente arrecadado no período. Entre os incentivos estabelecidos estão desconto de $15 \%$ para pagamento do imposto em cota única e sorteios de prêmios, como automóveis, eletrodomésticos e eletrônicos.

A Tabela 1 a seguir, elaborada com referência em dados disponíveis no portal da transparência do município de Itabuna, Bahia, ilustra o desempenho da arrecadação do Imposto sobre a Propriedade Predial e Territorial Urbana (IPTU) nos últimos 10 (dez) anos, por meio da relação entre a receita realizada e a previsão inicial da receita.

Página 214 Caderno de Ciências Sociais Aplicadas, Vitória da Conquista/BA, vol. 15, n 26, ano 15, p. 205-221, jul/dez 2018. 


\section{- Cadernos de CiêncIas SOCIAIS APLICADAS}

Tabela 1 - Desempenho da arrecadação do IPTU nos últimos 10 (dez) anos.

\begin{tabular}{l|c|c|c}
\hline Ano & Previsão inicial & Receitas realizadas & QDA (\%) \\
\hline 2005 & - & $\mathrm{R} \$ 1.502 .461,36$ & - \\
2006 & - & $\mathrm{R} \$ 1.444 .200,31$ & - \\
2007 & $\mathrm{R} \$ 2.000 .000,00$ & $\mathrm{R} \$ 2.009 .033,88$ & $100,45 \%$ \\
2008 & $\mathrm{R} \$ 2.400 .000,00$ & $\mathrm{R} \$ 2.435 .894,47$ & $101,50 \%$ \\
2009 & $\mathrm{R} \$ 2.600 .000,00$ & $\mathrm{R} \$ 2.957 .102,97$ & $113,73 \%$ \\
2010 & $\mathrm{R} \$ 3.200 .000,00$ & $\mathrm{R} \$ 3.389 .872,38$ & $105,93 \%$ \\
2011 & $\mathrm{R} \$ 4.716 .000,00$ & $\mathrm{R} \$ 3.672 .971,50$ & $77,88 \%$ \\
2012 & $\mathrm{R} \$ 3.000 .000,00$ & $\mathrm{R} \$ 4.503 .172,32$ & $150,11 \%$ \\
2013 & $\mathrm{R} \$ 7.542 .000,00$ & $\mathrm{R} \$ 5.125 .882,56$ & $67,96 \%$ \\
2014 & $\mathrm{R} \$ 6.000 .000,00$ & $\mathrm{R} \$ 5.705 .400,29$ & $95,09 \%$ \\
2015 & $\mathrm{R} \$ 8.750 .000,00$ & $\mathrm{R} \$ 7.362 .645,32$ & $84,14 \%$ \\
\hline
\end{tabular}

Fonte: Dados da pesquisa (2016).

Com fundamento na análise do Quociente de Desempenho da Arrecadação (QDA), Tabela 1, é possível evidenciar que, apesar de as receitas arrecadadas não terem alcançado o previsto, houve impactos positivos nas receitas do IPTU se comparadas ao ano de 2012. Levando em consideração a previsão de arrecadação e a realização das receitas do ano anterior, nota-se também que, em 2012, a previsão de arrecadação do IPTU fora subestimada, uma vez que as receitas realizadas em 2011 foram superiores à previsão de receitas daquele ano. Em 2013, nota-se uma superestimação das receitas, justificando a redução do QDA no primeiro ano de implementação do IPTU Premiado.

O gráfico 1 apresenta o desempenho da arrecadação do IPTU nos últimos 10 (dez) anos, de forma a evidenciar o aumento significativo da arrecadação do imposto, principalmente a partir de 2013, ano do início do programa. 


\section{Cadernos de CiênCIas SOCIAIS APLICADAS}

Gráfico 1 - Arrecadação do IPTU nos últimos 10 (dez) anos.

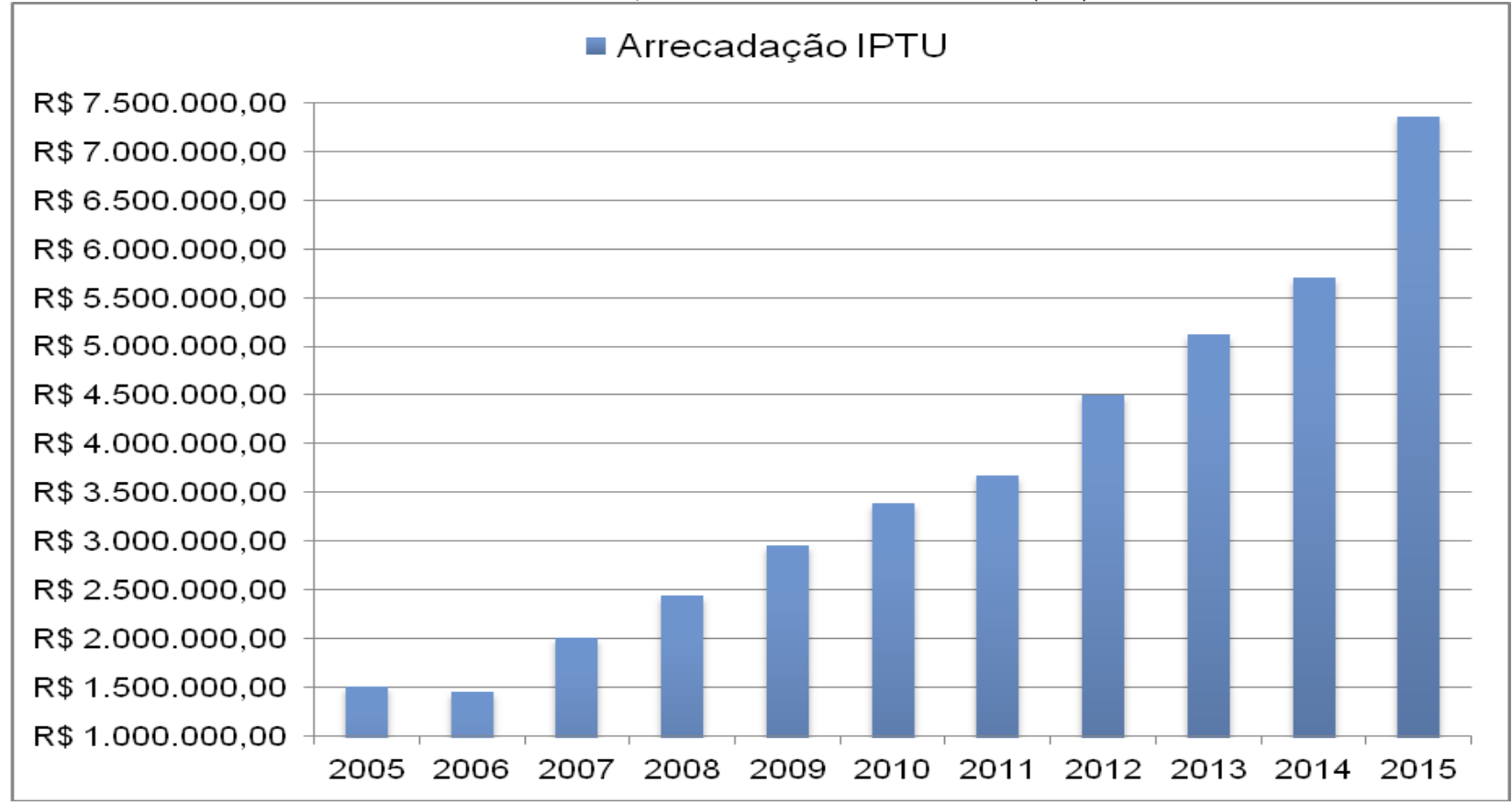

Fonte: Dados da pesquisa (2016).

A Tabela 2 apresenta a participação do IPTU na arrecadação tributária total do município ao longo dos últimos $10(\mathrm{dez})$ anos.

Tabela 2 - IPTU versus Receita Corrente Tributária.

\begin{tabular}{l|c|c|c}
\hline Ano & Arrecadação total & Arrecadação IPTU & IPTU / Receita total \\
\hline 2005 & $\mathrm{R} \$ 10.412 .165,90$ & $\mathrm{R} \$ 1.502 .461,36$ & $14,43 \%$ \\
2006 & $\mathrm{R} \$ 11.806 .360,42$ & $\mathrm{R} \$ 1.444 .200,31$ & $12,23 \%$ \\
2007 & $\mathrm{R} \$ 14.644 .564,63$ & $\mathrm{R} \$ 2.009 .033,88$ & $13,72 \%$ \\
2008 & $\mathrm{R} \$ 17.125 .849,82$ & $\mathrm{R} \$ 2.435 .894,47$ & $14,22 \%$ \\
2009 & $\mathrm{R} \$ 20.972 .794,17$ & $\mathrm{R} \$ 2.957 .102,97$ & $14,10 \%$ \\
2010 & $\mathrm{R} \$ 25.178 .330,90$ & $\mathrm{R} \$ 3.389 .872,38$ & $13,46 \%$ \\
2011 & $\mathrm{R} \$ 25.288 .493,67$ & $\mathrm{R} \$ 3.672 .971,50$ & $14,52 \%$ \\
2012 & $\mathrm{R} \$ 31.457 .138,46$ & $\mathrm{R} \$ 4.503 .172,32$ & $14,32 \%$ \\
2013 & $\mathrm{R} \$ 28.775 .001,10$ & $\mathrm{R} \$ 5.125 .882,56$ & $17,81 \%$ \\
2014 & $\mathrm{R} \$ 32.117 .003,75$ & $\mathrm{R} \$ 5.705 .400,29$ & $17,76 \%$ \\
2015 & $\mathrm{R} \$ 38.852 .765,99$ & $\mathrm{R} \$ 7.362 .645,32$ & $18,95 \%$ \\
\hline
\end{tabular}

Fonte: Dados da pesquisa (2016). 


\section{- Cadernos de Ciênclas SOCIAIS APLICADAS}

O gráfico 2 demonstra a evolução do IPTU nas receitas correntes municipais, evidenciando a eficiência do programa, com destaque para 2013, primeiro ano da campanha, cuja arrecadação total apresentou um índice de 17,81\%. Em 2015, último ano de observação, o crescimento acumulado foi de 38,84\% em relação a 2012. Entretanto, uma peculiaridade ocorrida naquele ano influenciou de forma significativa os resultados. O município adotou procedimentos de recadastramento imobiliário, por meio de mudanças de categorias de imóveis, conforme decreto publicado no diário oficial do município.

Gráfico 2 - Participação do IPTU em relação às receitas correntes.

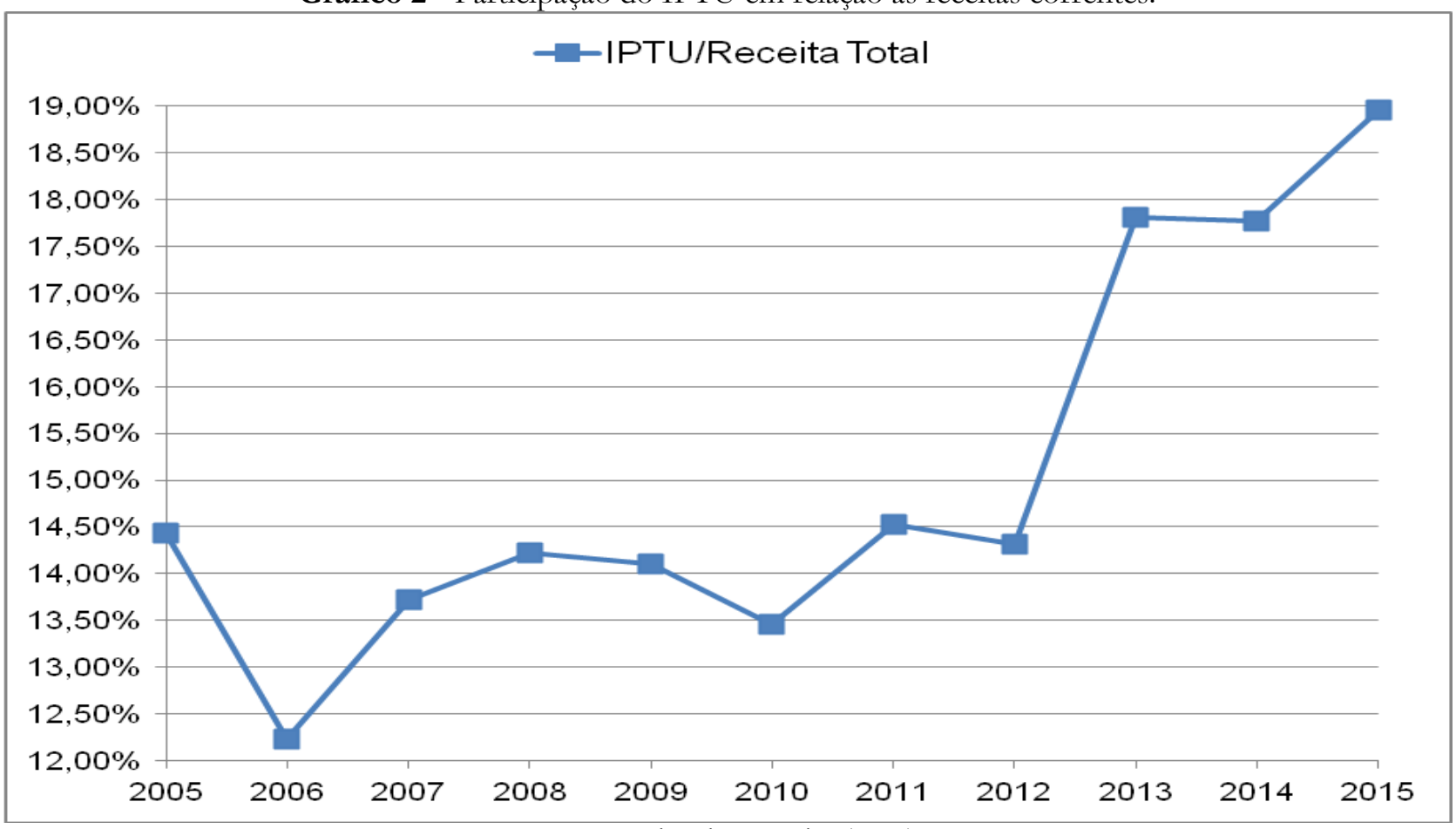

Fonte: Dados da Pesquisa (2016).

Para atingir o objetivo de aumentar a arrecadação do IPTU no município, a Lei Municipal $n^{\circ}$ 2.225/2013 fixou um percentual de 10\% da arrecadação do imposto para aquisição de prêmios a serem distribuídos entre os contribuintes que atendessem aos requisitos da promoção. No primeiro ano da campanha (2013) foram sorteados um carro zero $\mathrm{km}$, uma motocicleta zero $\mathrm{km}$ e um notebook. Em 2014, segundo ano da campanha, um carro zero $\mathrm{km}$, duas motocicletas zero $\mathrm{km}$, uma máquina de lavar e um notebook. Em 2015, com a consolidação da política foram sorteados trinta e dois prêmios, entre eles: dois carros zero km; oito motos zero km; sete notebooks; seis máquinas de lavar; seis bicicletas e três televisores.

Página 217 Caderno de Ciências Sociais Aplicadas, Vitória da Conquista/BA, vol. 15, n 26, ano 15, p. 205-221, jul/dez 2018. 
A Tabela 3, elaborada com base nos dados disponíveis no portal da transparência do município, apresenta o percentual aplicado na aquisição da premiação, no período de 2013 a 2015.

Tabela 3 - Despesas com aquisição de prêmios para a campanha "IPTU Premiado"

\begin{tabular}{c|c|c|c}
\hline Ano & Arrecadação IPTU & Despesas & \\
\hline 2013 & $\mathrm{R} \$ 5.125 .882,56$ & $\mathrm{R} \$ 122.945,00$ & $2,40 \%$ \\
2014 & $\mathrm{R} \$ 5.705 .400,29$ & $\mathrm{R} \$ 130.050,00$ & $2,28 \%$ \\
2015 & $\mathrm{R} \$ 7.362 .645,32$ & $\mathrm{R} \$ 113.250,00$ & $1,54 \%$ \\
\hline
\end{tabular}

Fonte: Dados da pesquisa (2016).

A relação entre a arrecadação do IPTU e as despesas de aquisição de prêmios, tabela 3, demonstra que a campanha foi vantajosa para o município, o desembolso para aquisição de prêmios não excedeu o percentual fixado.

Ao verificar os resultados da pesquisa constatou-se que, de fato, a política de arrecadação "IPTU Premiado" de Itabuna, na Bahia, gerou um considerável crescimento nas receitas próprias do município. Contudo, faz-se necessário um novo estudo para avaliar a efetividade do IPTU Premiado nos anos seguintes aos avaliados neste estudo. Todavia, a partir de 2017, com a mudança de gestão do executivo municipal, nenhuma lei foi instituída para a manutenção da política de incentivo à arrecadação, apesar da avaliação positiva tanto no que se refere aos dados quanto à analise da população.

\section{Considerações finais}

Esta pesquisa teve o objetivo de verificar a eficiência da política de arrecadação "IPTU Premiado" nas receitas orçamentárias de Itabuna, Bahia. Foram analisadas as receitas dos últimos dez anos do município. Os achados desta pesquisa comprovam que o objetivo do estudo foi alcançado e contribui para que os gestores possam realizar melhoria no processo arrecadatório.

Quanto ao problema que norteou este trabalho, foi possível concluir que o IPTU Premiado foi uma estratégia de arrecadação que contribuiu consideravelmente para o aumento $(38,84 \%)$ das receitas orçamentárias. A limitação da pesquisa ocorre porque em alguns anos pesquisados não foram encontrados valores referentes à previsão das receitas. Como sugestão de pesquisas futuras, recomendase realizar estudos voltados para outras políticas de estímulo à arrecadação tributária.

Página 218 Caderno de Ciências Sociais Aplicadas, Vitória da Conquista/BA, vol. 15, n 26, ano 15, p. 205-221, jul/dez 2018. 
Este estudo pode contribuir para que gestores públicos tenham o conhecimento de metodologias capazes de oferecer um melhor desempenho na arrecadação das receitas públicas. Estudos voltados para investigar e avaliar metodologias para a melhoria da arrecadação tributária, principalmente nos municípios, são imprescindíveis.

\section{Referências}

AFONSO, José Roberto Rodrigues; ARAÚJO, Erika Amorim; NÓBREGA, Marcos Antonio Rios da. O IPTU no Brasil: um diagnóstico abrangente. 2013.

ALCOFORADO, Flávio. O Instituto de Governança Social: avanços e perspectivas no desenho de um novo arranjo organizacional. 2009.

ALEXANDRE, Ricardo. Direito Tributário Esquematizado. - 9. ed. rev., atual. e ampl. - Rio de Janeiro Forense; São Paulo, 2015.

BÍBLIA, Português. A Bíblia Sagrada: Antigo e Novo Testamento. Tradução de João Ferreira de Almeida. Edição rev. e atualizada no Brasil. Brasília: Sociedade Bíblia do Brasil, 1969.

BRASIL. Constituição Federal de 1988. Disponível em: <http://www.planalto.gov.br>. Acesso em: 10 fev. 2016.

CARVALHO JR, Pedro Humberto Bruno de. IPTU no Brasil: progressividade, arrecadação e aspectos extra-fiscais. 2006.

COSTA, Alcides Jorge. Reforma tributária: uma visão histórica. Revista da Faculdade de Direito, Universidade de São Paulo, v. 89, p. 207-217, 1994.

DIAS, Rui Pedro Viveiros Pereira. A composição ótima do financiamento municipal: modelos de financiamento local no contexto europeu e o caso Português. 2013. Tese de Doutorado. Instituto Superior de Economia e Gestão.

DUARTE, João Alfredo Albano; ALCÂNTARA, Silvano Alves. O impacto da arrecadação do IPTU no orçamento público do Município de Francisco Santos/PI. Caderno Gestão Pública, v. 2, n. 1, p. 73-96, 2013

GARSON, Sol. O IPTU como instrumento de política pública no contexto da lei de responsabilidade fiscal. CURSO DE GESTÃO URBANA E DE CIDADES, 2001.

GIL, Antonio Carlos. Métodos e técnicas de pesquisa social. In: Métodos e técnicas de pesquisa social. Atlas, 2008.

ITABUNA. Portal da Prefeitura Municipal de Itabuna. Disponível em: <http://www.itabuna.ba.io.org.br/diarioOficial>. Acesso em: 18 abr. 16.

Página 219 Caderno de Ciências Sociais Aplicadas, Vitória da Conquista/BA, vol. 15, n 26, ano 15, p. 205-221, jul/dez 2018. 
ITABUNA. Portal da Transparência da Prefeitura de Itabuna. Disponível em: $<$ https://itabunaba.portaltp.com.br/>. Acesso em: 18 abr. 16.

ITABUNA. Sistema Eletrônico de Informação ao Cidadão. Disponível em: < http://www.itabuna.ba.io.org.br/sic_novo/>. Acesso em: 13 set. 16.

ITABUNA. Portal da Transparência Imprensa Oficial Prefeitura Municipal de Itabuna. Disponível em: $<$ http:/ / ba.portaldatransparencia.com.br/prefeitura/itabuna/index.cfm?pagina $=$ lrf\&frompage $=1 \&$ Star tRow=6\&lrf_tipo_id=1>. Acesso em: 18 out. 16.

. Lei Complementar n. 2.225, de 05 de Março de 2013 (Lei do IPTU Premiado).

KALIL, Gilberto Alexandre de Abreu; GONÇALVES, Oksandro Osdival. Incentivos fiscais à inovação tecnológica como estímulo ao desenvolvimento econônimo: o caso das Startups. Revista Jurídica da Presidência, v. 17, n. 113, p. 497-520, 2016.

KNOPP, Glauco; ALCOFORADO, Flávio. Governança social, intersetorialidade e territorialidade em políticas públicas: o caso da Oscip Centro Mineiro De Alianças Intersetoriais (Cemais). 2010.

LONGO, Rene Furtado. A tributação no Estado Democrático de Direito. ENCONTRO DE ESTUDOS TRIBUTÁRIOS, v. 1, p. 1-13, 2006.

MARINI, Caio. Além da gestão pública: a emergência da governança social para o desenvolvimento. Revista Governança Social Ano, v. 1, 2008.

MINAYO, Maria Cecília de Souza et al. Pesquisa social: teoria, método e criatividade. Vozes, 2001.

RODRIGUES, Kaliana Guimarães. Dinâmica urbana no município de Itabuna (Ba) : / o mercado imobiliário e as políticas urbanas $(1990$ - 2010) Dissertação (Mestrado em Geografia) Instituto de Geociências, Universidade Estadual de Campinas. São Paulo, p. 263. 2012. Disponível em: http://repositorio.unicamp.br/bitstream/REPOSIP/287289/1/Rodrigues_KalianaGuimaraes_M.pdf >. Acesso em: 10 dez. 2018.

ROTHMANN, Gerd W. O princípio da legalidade tributária. Revista da Faculdade de Direito, Universidade de São Paulo, v. 67, p. 231-268, 1972.

SÁ, José Delfino. Um modelo para o IPTU dos imóveis residenciais que visa incentivar a sustentabilidade urbana. 2015.

SOARES, Cristiano Sausen; FLORES, Silvia Amélia Mendonça; CORONEL, Daniel Arruda. O Comportamento da Receita Pública Municipal Um Estudo de Caso no Município de Santa Maria (RS). Desenvolvimento em Questão, v. 12, n. 25, p. 312-338, 2014.

Página 220 Caderno de Ciências Sociais Aplicadas, Vitória da Conquista/BA, vol. 15, n 26, ano 15, p. 205-221, jul/dez 2018. 
SCHWELLA, Erwin. Inovação no governo e no setor público: desafios e implicações para a liderança. Revista do Serviço Público, v. 56, n. 3, p. 259-276, 2014.

SILVA, Thaís Santos et al. INOVAÇÃo NA ADMINISTRAÇÃO PÚBLICA: Um Meta Estudo dos Anais do EnAnpad. 2014.

VARSANO, Ricardo. A evolução do sistema tributário brasileiro ao longo do século anotações e reflexões para futuras reformas. 1996. 